\title{
Unexplained fetal growth retardation: what is the cause?
}

\author{
Ashley King, Y W Loke
}

Recent epidemiological studies suggest a link between reduced fetal growth and the subsequent development of hypertension and diabetes in adult life. ${ }^{1-5}$ An understanding of the aetiology of fetal growth retardation is therefore of increased importance. Fetal adaptations to an adverse uterine environment, of which low birth weight is the most obvious marker, may 'programme' an individual in such a way that organs become permanently defective in their structure, physiology, or regulatory function. ${ }^{6}$ Although there are many causes of growth retardation (for example viral infection and smoking), ${ }^{7}$ the babies in these epidemiological studies fall into the category of idiopathic intrauterine growth retardation (IUGR). We believe that this reduced fetal growth is due to poor development of the maternal blood supply to the fetoplacental unit because of defective interaction between placental trophoblast cells and cells of the maternal uterine mucosa, the decidua.

The evidence indicates that non-genetic maternal influences, rather than the fetal genotype, are of primary importance in determining birth weight. ${ }^{8}$ What maternal factors should be considered? In many published papers it is implied that maternal undernutrition is an important cause of impaired fetal growth. ${ }^{39}$ Although this is true in cases of sudden starvation $^{10}$ or of chronic malnutrition, this explanation is unlikely to apply in developed countries, ${ }^{7}$ and indeed the phenomenon is largely independent of social class. ${ }^{15}$

Fetal growth and nutrition obviously depend on an adequate supply of nutrients via the placenta and therefore on the maternal blood flow to the intervillous space. Crucially important in this respect is the transformation of the maternal spiral arteries in the first trimester. ${ }^{11}$ In normal pregnancy the walls of the muscular spiral arteries are destroyed, and the vessels transformed into low resistance sinusoidal sacs capable of delivering a high constant flow of blood at low pressure (and independently of autonomic responses) throughout pregnancy. Notably this process is initiated early in gestation and is completed by 16-18 weeks. The transformation is effected by placental trophoblast cells invading the arterial wall, from the inside by migration down the lumen of the vessel, and from the outside by infiltration into the decidua. ${ }^{12}$ Failure of this process will lead to a compro- mised blood supply to the fetoplacental unit and its presence in IUGR has been shown by histological examination of pregnant hysterectomy specimens and placental bed biopsies. It was noted that in many cases of IUGR the trophoblast invasion of decidual spiral arteries was inadequate in terms of the number of vessels invaded and the depth of invasion. ${ }^{13} 14$ In normal pregnancy the vascular transformation extends well into the myometrium whereas this does not occur in IUGR. Aetiological explanations do need to take into account the different patterns of growth retardation which, in the epidemiological studies, were associated with the development of hypertension in later life. Babies may have a low birth weight, or be thin or short at birth. The placenta can be large in relation to body weight, ${ }^{9}$ and the highest blood pressures were found in those people who had been short babies with large placentas. ${ }^{5}$

The presence of a large placenta in one pattern of growth retardation may be explained by the ability of the placenta to undergo compensatory hypertrophy if the maternal blood supply is only moderately impaired. If the reduced blood supply results in hypoxia in the intervillous space, the placenta tends to enlarge in an attempt to increase the surface area available for transfer of oxygen and nutrients to the fetus. In such cases the placenta is large relative to the size of the baby. Indeed other causes of hypoxia, such as anaemia ${ }^{15}$ and high altitude ${ }^{16}$ also result in larger placentas. In the other pattern of poor fetal growth in which babies are thin at birth, the maternal blood supply is more severely impaired and the placenta presumably cannot respond by hypertrophy and therefore both fetus and placenta are small.

Interestingly, histological studies have also identified the association of maternal preeclampsia with inadequate trophoblast transformation of decidual arteries, ${ }^{17} 18$ so that IUGR and pre-eclampsia seem to share a common aetiology of poor placental perfusion. Poor fetal growth in utero is seen in both conditions but in pre-eclampsia there is a superimposed maternal systemic syndrome. This could explain Barker and Osmond's original observation that the mortality from cardiovascular disease in adults correlated to past maternal mortality from toxaemia around 70 years ago. ${ }^{19}$ It would also explain the fact 
that blood pressure is more closely related to maternal than paternal systolic pressure..$^{20}$

To elucidate the pathological defects underlying IUGR and pre-eclampsia, the priority for research, therefore, should be to address the mechanisms controlling the interaction between invading trophoblast and uterine decidua, rather than to focus on maternal nutrition. At present, it is not known how vascular invasion by trophoblast is controlled. Decidua must provide an important restraining influence on trophoblast behaviour, for when implantation occurs on sites where decidua is sparse (as in ectopic pregnancies or placenta percreta) trophoblast over invades causing rupture of organs. ${ }^{18}$ Conversely the decidual defences against trophoblast invasion must work too well in pre-eclampsia and IUGR. Decidua exhibits many characteristic features. For example there is deposition of a specialised extracellular matrix which includes laminin and fibronectin. The interaction of trophoblast with these matrix proteins via expression of appropriate integrins and production of proteases by trophoblast, would be important areas for future investigation. ${ }^{21}$ Also a variety of cytokines are demonstrable at the implantation site in decidua. It would be pertinent to identify the cellular sources of these cytokines and define their activity. Many of these were first described as regulators of bone marrow proliferation and differentiation (for example colony stimulating factor-1, granulocyte-macrophage colony stimulating factor, leukaemia inhibitory factor $)^{22}$ and may play a similar part in regulation of trophoblast differentiation as it moves into uterine tissues.

It is of particular interest, though, that the process of implantation involves the intermingling of cells from two genetically different individuals, so its success appears to defy the laws of transplantation immunity. Thus, the trophoblast cells moving through the maternal uterine tissues to destroy and replace the arterial walls are foreign to the mother. However, it has now been demonstrated that although invading trophoblast does not express normal classical HLA class I transplantation antigens, it does express a product of the nonclassical class I HLA-G gene instead. ${ }^{23}$ At the same time the decidua is infiltrated by large numbers of distinctive, apparently uterine specific, large granular lymphocytes/natural killer cells (LGL/NK) with unusual phenotype which are not seen in any other adult organ. ${ }^{24}$ Because these uterine leucocytes are physically so closely associated with invading trophoblast and infiltrate the uterus at the same time, it is possible that their interaction with trophoblast could provide an important element of control. Although the function of HLA-G is not known, class I molecules can be recognised by peripheral blood NK cells, even though NK cells lack the CD3-T cell receptor complex. ${ }^{25} 26$ One intriguing possibility is that uterine LGL/NK cells have receptors which can 'recognise' HLA-G and are then triggered to perform various effector functions that can influence trophoblast behaviour. This would be a novel recognition system reminiscent of primitive defence mechanisms used by invertebrates.

Efforts to study placental implantation are hampered by the fact that other species, even those with haemochorial placentation, do not exhibit the same degree of trophoblast invasion and vascular transformation and, therefore, cannot be used for experimentation. In particular, extrapolation of data from those species with epitheliochorial placentation, such as sheep, is unlikely to be valid. It is necessary to create valid in vitro models using human tissues, but these studies are not easy to perform as they require the selective isolation of the various cell types from the fetomaternal interface. Trophoblast, in particular, is notoriously difficult to isolate to a sufficient degree of purity for in vitro experimentation. However, these technical difficulties are beginning to be resolved, ${ }^{27}$ and appropriate experiments can be devised. It is in vitro studies such as these that will determine the mechanisms by which maternal blood supply to the placenta is controlled and hence reveal the factors which will ultimately influence fetal growth in utero.

1 Barker DJP, Winter PD, Osmond C, Margetts B, Simmonds SJ. Weight in infancy and death from ischaemic heart disease. Lancet 1989; ii: 577-80.

2 Barker DJB, Osmond C, Golding J, Kuh D, Wadsworth MEJ. Growth in utero, blood pressure in childhood and adult life, and mortality from cardiovascular disease. $B M \mathcal{F}$ 1987; 295: 83-6.

3 Barker DJB, Osmond C, Simmonds SJ, Wield GA. The relation of small head circumference and thinness at birth to death from cardiovascular disease in adult life. $B M \mathcal{A}$ 10 death from cardic

4 Law CM, de Swiet M, Osmond C, et al. Initiation of hypertension in utero and its amplification throughout life. BMF 1993; 306: 24-7.

5 Barker DJP, Bull AR, Osmond C. Fetal and placental size and risk of hypertension in adult life. BMF 1990; 301 259-62

6 Lucas A. Programming by early nutrition in man. In: Buck GR, Whelan J, eds. The childhood environment and adult disease. Ciba Foundation 156. Chichester: John Wiley, 1991: $38-55$

7 Wigglesworth JS. Aetiology of fetal undergrowth. In: Sharp F, Fraser RB, Milner RDG, eds. Fetal growth. London: Foyal College of Obstetricians and Gynaecologists, 1989: Royal Co.

8 Yates JRW. Genetics of fetal and postnatal growth. In: Cockburn F, ed. Fetal and neonatal growth. Chichester: John Wiley, 1988: 1-10

9 Barker DJP, Gluckman PD, Godfrey KM, Harding JE Owens JA, Robinson JS. Fetal nutrition and cardiovascular disease in adult life. Lancet 1993; 341: 938-41.

10 Crouse JR. Ischaemic heart disease. Reduced height for weight and cardiovascular disease. Lancet 1993; 341: $931-2$

11 Pijnenborg R. Trophoblast invasion and placentation in the human: morphological aspects. Trophoblast Research 1990 4: $33-47$.

12 Pijnenborg R, Bland JM, Robertson WB, Brosens I. Uteroplacental arterial changes related to interstitial Uteroplacental arterial changes related to interstitial trophoblast migratio

13 Khong TY, DeWolf F, Robertson WB, Brosens I. Inadequate maternal vascular response to placentation in pregnancies complicated by pre-eclampsia and by smallfor-gestational age infants. Br F Obstet Gynaecol 1986; 93 1049-59.

14 Pijnenborg R, Anthony J, Davey DA, et al. Placental bed spiral arteries in the hypertensive disorders of pregnancy. Br 7 Obstet Gynaecol 1991; 98: 648-55.

15 Godfrey KM, Redman CWG, Barker DJP, Osmond C. The effect of maternal anaemia and iron deficiency on the ratio of fetal weight to placental weight. Br f Obstet Gynaecol 1991; 98: 886-91.

16 Kruger H, Arias Stella J. The placentas and the newborn infant at high altitudes. Am $\mathcal{F}$ Obstet Gynecol 1970; 105: 586 .

17 Brosens I, Robertson WB, Dixon HG. The role of the spiral arteries in the pathogenesis of pre-eclampsia. Obstetrics arteries in the pathogenesis of pre-eclam

18 Robertson WB. Pathology of the pregnant uterus. In: Fox $\mathrm{H}$, ed. Haines and Taylor. Obstetrical and gynaecological $\mathrm{H}$, ed. Haines and Taylor. Obstetrical and gynaecological pathology. 3rd

19 Barker DJP, Osmond C. Death rates from stroke in England and Wales predicted from past maternal mortality. $B M \mathcal{F}$ 1987; 295: 83-6. 
20 Law CM, Barker DJP, Bull AR, Osmond C. Maternal and fetal influences on blood pressure. Arch Dis Child 1991; 66: 1291-5.

21 Fisher SJ, Damsky CH. Human cytotrophoblast invasion. Semin Cell Biol 1993; 4: 183-8.

22 Mitchell MD, Trautman MS, Dudley DJ. Cytokine networking in the placenta. Placenta 1993; 14: 249-75.

23 Kovats S, Main EK, Librach C, Stubblebine M, Fisher SJ, DeMars R. A class I antigen, HLA-G, expressed in human trophoblast. Science 1990; 248: 220-3.
24 King A, Loke YW. On the nature and function of human uterine granular lymphocytes. Immunol Today 1991; 12: 432-5.

25 Raulet DH. A sense of something missing. Nature 1992; 358: $21-2$.

26 Moretta L, Ciccone E, Moretta A, Hoglund P, Ohten C Karre K. Allorecognition by NK cells: nonself or no self? Immunol Today 1992; 13: 300-6. 27 Loke YW, King A. Recent developments in the human maternal-fetal immune interaction. Curr Opin Immunol 1991; 3: 762-6. 